\title{
The Behavior of Novel Hydrophilic Composite Bone Cements in Simulated Body Fluids
}

\author{
Luciano F. Boesel, ${ }^{1,2}$ Maria H. V. Fernandes, ${ }^{3}$ Rui L. Reis ${ }^{1,2}$ \\ ${ }^{1}$ 3B's Research Group-Biomaterials, Biodegradables and Biomimetics, University of Minho, Campus of Gualtar, \\ 4710-057, Braga, Portugal \\ ${ }^{2}$ Department of Polymer Engineering, University of Minho, Campus of Azurém, 4800-058, Guimarães, Portugal \\ ${ }^{3}$ Department of Ceramics and Glass Engineering, University of Aveiro, 3810-193, Aveiro, Portugal
}

Received 27 August 2003; revised 15 December 2003; accepted 23 December 2003

Published online 10 May 2004 in Wiley InterScience (www.interscience.wiley.com). DOI: 10.1002/jbm.b.30055

\begin{abstract}
Composite bone cements were formulated with bioactive glass $\left(\mathrm{MgO}-\mathrm{SiO}_{2}-3 \mathrm{CaO}\right.$ $\mathrm{P}_{2} \mathrm{O}_{5}$ ) as the filler and hydrophilic matrix. The matrix was composed of a starch/cellulose acetate blend (SCA) as the solid component and a mixture of methylmethacrylate/acrylic acid (MMA/AA) as the liquid component. The curing parameters, mechanical properties, and bioactive behavior of these composite cements were determined. The addition of up to $30 \mathrm{wt} \%$ of glass improved both compressive modulus and yield strength and kept the maximum curing temperature at the same value presented by a typical acrylic-based commercial formulation. The lack of a strongly bonded interface (because no coupling agent was used) had important effects on the swelling and mechanical properties of the novel bone cements. However, bone cements containing AA did not show a bioactive behavior, because of the deleterious effect of this monomer on the calcium phosphate precipitation on the polymeric surfaces. Formulations without AA were prepared with MMA or 2-hydroxyethyl methacrylate (HEMA) as the liquid component. Only these formulations could form an apatite-like layer on their surface. These systems, therefore, are very promising: They are bioactive, hydrophilic, partially degradable, and present interesting mechanical properties. This combination of properties could facilitate the release of bioactive agents from the cement, allow bone ingrowth in the cement, and induce a press-fitting effect, improving the interfaces with both the prosthesis and the bone. () 2004 Wiley Periodicals, Inc. J Biomed Mater Res Part B: Appl Biomater 70B: $368-377,2004$
\end{abstract}

Keywords: bone cement; starch; bioactive glass; composites; HEMA

\section{INTRODUCTION}

Conventional acrylic bone cements, despite the long-term research aimed to improve their properties, still present several problems. These include ${ }^{1-3}$ thermal necrosis of bone due to the high exothermic temperature of the cement polymerization, chemical necrosis of bone due to the release of unreacted MMA, shrinkage during polymerization, weakness of the cement (and the interfaces) when compared with the prosthesis and the bone, and stress shielding of the bone due to improper transfer of load. Many alternatives were developed to overcome these problems, such as the incorporation of bioactive fillers to improve the

Correspondence to: Luciano F. Boesel, Department of Polymer Engineering, University of Minho, Campus of Azurém, 4800-058, Guimarães, Portugal (e-mail: lfboesel@dep.uminho.pt)

Contract grant sponsor: Fundação Coordenação de Aperfeiçoamento de Pessoal do Ensino Superior (CAPES-Brasília, Brasil)

Contract grant sponsor: FCT Foundation for Science and Technology

CC 2004 Wiley Periodicals, Inc. mechanical properties and increase the adhesion to bone, ${ }^{4}$ the development of novel formulations with higher ductility and lower tensile modulus to produce a more even stress distribution between the prosthesis and the bone, ${ }^{5}$ and the use of adhesive additives to increase adhesion between bone and the metal prosthesis and minimize the gap between the interfaces, ${ }^{6}$ the modification of the liquid phase in order to decrease the thermal and chemical damage to tissue, ${ }^{7}$ and the development of twosolution bone cements. ${ }^{8}$

Hydrophilic bone cements (HBCs) are another recent alternative. ${ }^{1,9}$ They contain a hydrogel-forming monomer (AA, HEMA) in the liquid component of the typical bone- cement formulation, partially substituted for MMA in order to adjust the mechanical and the swelling properties of the system. Therefore, the key characteristics of the hydrophobic acrylic cements, such as fast polymerization rate, injectability, and high mechanical properties, are maintained; and the advantages of hydrogels - good compatibility with body fluids and tissues, improved release behavior of drugs, easier bioactivity $^{10}$ and others-are added. 
These hydrophilic bone cements also incorporate a starchbased blend that can degrade in the body and has already been studied for a range of biomedical applications such as scaffolds for tissue engineering, ${ }^{11}$ systems for drug delivery, ${ }^{12}$ and proposed bone replacement and regeneration applications. ${ }^{13}$ Previous reports have shown that the swelling kinetics of HBCs depends on the $\mathrm{pH}$ of the surrounding medium, ${ }^{9}$ that the amount of residual monomer is very low $(<1 \mathrm{~mol}$ $\%),{ }^{14}$ and that the molar ratio of monomers used determined the swelling kinetics and extent. ${ }^{15}$ They could become bioactive by the addition of bioactive fillers such as HA, as previously shown. ${ }^{14}$

This work reports on the development of composites of starch-based bone cements with a new kind of bioactive glass of the $3 \mathrm{CaO} \cdot \mathrm{P}_{2} \mathrm{O}_{5}-\mathrm{SiO}_{2}-\mathrm{MgO}$ system, which has already been used to induce the formation of a calcium phosphate layer on its surface. ${ }^{16}$ The aims of the incorporation of the glass were to improve the mechanical (compression) properties of the cements and to induce bioactivity on the system, while keeping (or improving) the curing parameters. These composites were characterized in terms of mechanical, curing, and swelling parameters. Their behavior under immersion in simulated body fluid (SBF) was also investigated.

\section{MATERIALS AND METHODS}

\section{Preparation of Bone Cements}

Specimens were prepared by adding the solid component to the liquid component. The solid was constituted by a commercial cornstarch/cellulose acetate 50/50 wt \% blend (SCA), obtained from Novamont (Novara, Italy) and a bioactive glass (BG) composed of $30.0 \% \mathrm{SiO}_{2}, 52.75 \% 3 \mathrm{CaO} \cdot \mathrm{P}_{2} \mathrm{O}_{5}$ and $17.25 \% \mathrm{MgO}$ (weight percentages). The glass had particle sizes of 1.2-60 $\mu \mathrm{m}$, and the polymer particles were smaller than $125 \mu \mathrm{m}$. The liquid was constituted by acrylic acid (AA) and methylmethacrylate (MMA), which were used as received. Benzoyl peroxide powder (BPO) was used as the polymerization initiator at a molar concentration of 0.01 with respect to the monomer amount. BPO was purified by fractional recrystallization from ethanol and subsequently vacuum dried (m.p. $104^{\circ} \mathrm{C}$ ). N-dimethylaminobenzyl alcohol $(\mathrm{DMOH})$ was used as the activator of the initiator, at a molar concentration of 0.67 with respect to the BPO amount. $\mathrm{DMOH}$ was synthesized following a previously described procedure. ${ }^{17}$ The solid/liquid ratio employed was $60 / 40$, the MMA/AA molar ratio was $2 / 1$, and the concentration of $\mathrm{BG}$ was varied from 0 to $30 \mathrm{wt} \%$ (of the total mass). These formulations were named as B0 (0\% BG), B1 (10\% BG), B2 (20\% BG), and B3 (30\% BG).

Other materials were used in this study to prepare additional formulations for bioactivity tests: nonsintered hydroxyapatite (HA, Plasma Biotal, United Kingdom), a commercial bioactive glass (Bioglass ${ }^{\circledR}$ 45S5, U.S. Biomaterials Corp.), and 2-hydroxyethyl-methacrylate (HEMA). The formulations prepared with these materials are shown in Table I, together
TABLE I. Formulations Prepared for Bioactivity Tests

\begin{tabular}{cll}
\hline Formulation & Solid Component $^{\mathrm{a}}$ & Liquid Component $^{\circ}$ \\
\hline A & BG & MMA $+\mathrm{AA}^{\mathrm{b}}$ \\
C & BG & MMA \\
D & SCA $+\mathrm{HA}^{\mathrm{c}}$ & MMA $+\mathrm{AA}^{\mathrm{b}}$ \\
E & $\mathrm{SCA}+$ Bioglass $^{\mathrm{c}}$ & MMA $+\mathrm{AA}^{\mathrm{b}}$ \\
F & $\mathrm{SCA}+\mathrm{BG}^{\mathrm{c}}$ & HEMA \\
G & SCA & HEMA \\
H & SCA + Bioglass $^{\mathrm{c}}$ & HEMA \\
\hline
\end{tabular}

${ }^{\text {a }}$ Solid/liquid ratio was $60 / 40$ in all formulations.

${ }^{\mathrm{b}}$ Molar ratio MMA/AA was $2 / 1$.

${ }^{\mathrm{c}} \mathrm{SCA} /$ filler ratio was $1 / 1$.

with their respective compositions. HA had particle sizes of 4.1-9.0 $\mu \mathrm{m}$, whereas Bioglass ${ }^{\circledR}$ exhibited a granulometric distribution between 38 and $53 \mu \mathrm{m}$. The particle sizes of HA and the glasses were determined by laser scattering analysis with the use of a model Coulter LS100 particle size analyzer.

The preparation of specimens for subsequent tests was carried out following the traditional method. The activator $\mathrm{DMOH}$ was dissolved in the liquid phase. Initiator of freeradical polymerization reaction was added to the solid phase. Both phases were mixed and stirred by hand until the mixture became paste-like with a high viscosity; the mass was then placed into a poly(tetrafluoroethylene) (PTFE) mold to allow it to cure. After $60 \mathrm{~min}$, one group of specimens was removed from the mold and put into an oven at $60^{\circ} \mathrm{C}$ until the group attained constant weight. Another group was stored at $23^{\circ} \mathrm{C}$ and $55 \%$ humidity.

Injection-molded discs of SCA, which were subjected to a wet chemical surface modification with $\mathrm{HNO}_{3}$ and $\mathrm{KMnO}_{4}$, were also used for bioactivity tests. These discs have previously been reported as able to induce an apatite-like layer on their surfaces after 7 days of immersion in SBF. ${ }^{18}$

A commercially available, acrylic-based bone cement (Palacos ${ }^{\circledR}$ R, Schering Plough, Belgium) was prepared by following the manufacturer's instructions. This was used as a control for comparative purposes.

\section{Curing Parameters}

Dough time $\left(t_{\mathrm{d}}\right)$, setting time $\left(t_{\mathrm{s}}\right)$, and maximum polymerization temperature $\left(T_{\max }\right)$ were measured with the use of a PTFE mold (diameter of $40 \mathrm{~mm}$ ), and a thermocouple connected to a digital thermometer with a precision of $\pm 1^{\circ} \mathrm{C}$. The apparatus was placed inside an oven kept at $37 \pm 1^{\circ} \mathrm{C}$. The powder and liquid components of bone cements (stored at $4{ }^{\circ} \mathrm{C}$ ) were mixed and packed into the PTFE mold when the mixture reached the dough state; the mold was closed with a plate containing a small passage in the center for the thermocouple. The thermocouple was located in the center of the curing mass. Setting time was considered as the time at which the temperature of the mass was the sum of the test temperature $\left(37^{\circ} \mathrm{C}\right)$ and maximum temperature $\left(T_{\max }\right)$ divided by two. This procedure was based on the ISO and ASTM standards for bone cements, ${ }^{19,20}$ with some modifications to better simulate the temperatures used during clinical practice. 


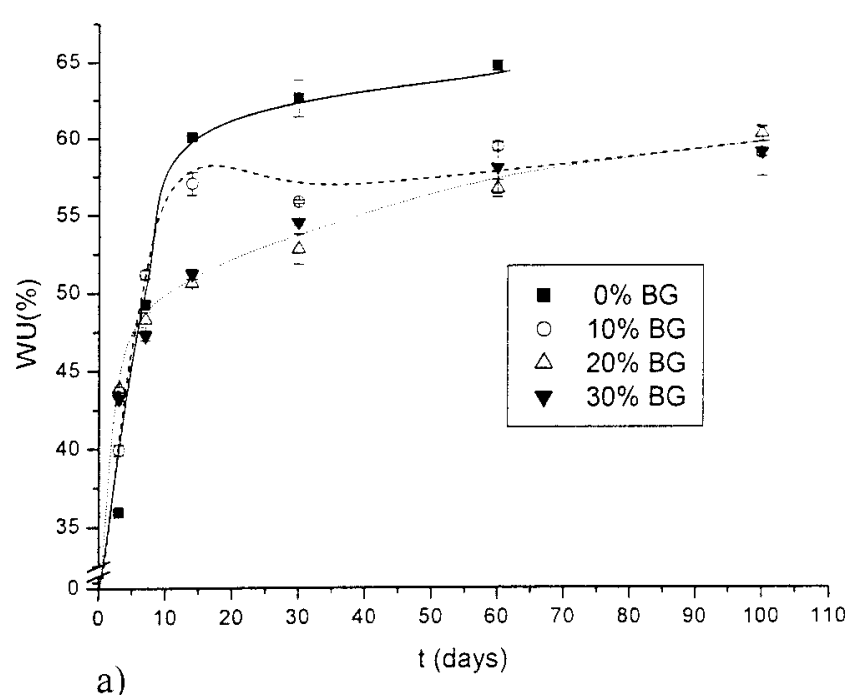

a)

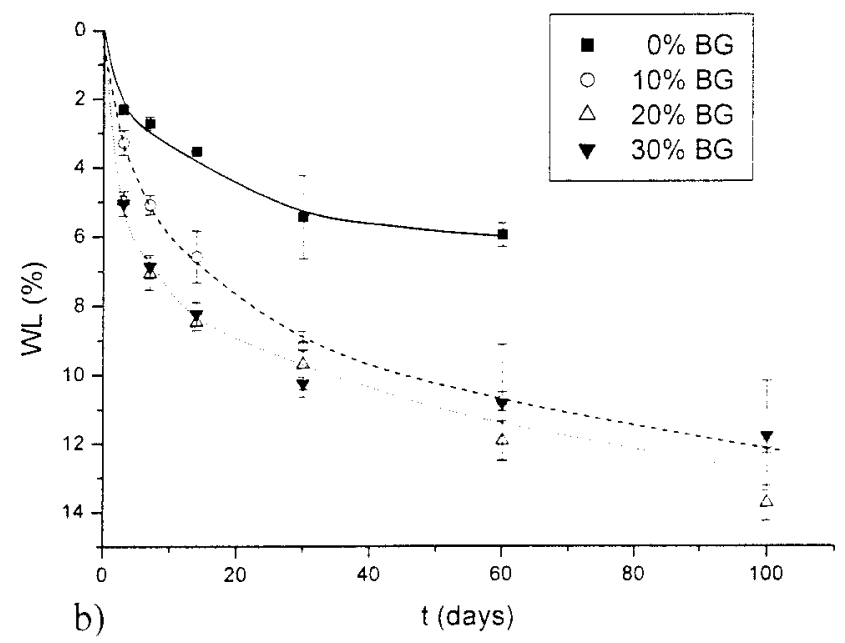

Figure 1. (a) Water uptake (WU) and (b) weight loss (WL) of the pure and composite formulations. Solid lines, 0\% BG, dashed lines, $10 \%$ BG, dotted lines, $20 \%$ and $30 \%$ BG

\section{Mechanical Properties}

Tensile and compressive tests were carried out at room temperature on an Instron 4505 Universal Mechanical Testing Machine with the use of a load cell of $50 \mathrm{kN}$. A minimum of five specimens was tested for each type of solicitation and each sample. The specimens were tested either after storage at $23^{\circ} \mathrm{C}$ and $55 \%$ humidity or after 7 days of immersion in an isotonic saline solution (ISS: $0.154 M \mathrm{NaCl}$ aqueous solution at $\mathrm{pH}$ 7.4) maintained at $37^{\circ} \mathrm{C}$. In this case, they were tested immediately after being removed from the solution.

For tensile characterization, cross-head speeds of $5 \mathrm{~mm} /$ min were employed. The average size of rectangular specimens for tensile tests was $3 \times 5 \times 30 \mathrm{~mm}$. Specimens for the compressive test were cylinders with $6-\mathrm{mm}$ diameter and $12-\mathrm{mm}$ height. The cross-head speed was $20 \mathrm{~mm} / \mathrm{min}$. Tests were carried out up to failure or until $60 \%$ reduction in specimen height.

\section{Hydration Degree and Degradation Behavior}

The water-uptake and the degradation of the prepared bonecement formulations were studied over a period of 100 days. Cylindrical specimens were conditioned to constant weight in an oven at $60^{\circ} \mathrm{C}$, before being immersed in ISS [15-mL solution per unit mass ( $\mathrm{g}$ ) of specimen]. The specimens were removed at intervals of $3,7,14,30,60$, and 100 days, rinsed with distilled water, blotted on filter paper to remove surface solution/water, and immediately weighed. They were then dried in the oven at $60^{\circ} \mathrm{C}$ to a constant weight in order to determine the weight loss. Water uptake (WU) and weight loss (WL) were calculated as follows:

$$
\begin{aligned}
& \mathrm{WU}_{\mathrm{t}}=\left[\left(m_{\mathrm{t}}-m_{\mathrm{f}, \mathrm{t}}\right) / m_{\mathrm{f}, \mathrm{t}}\right] * 100, \\
& \mathrm{WL}_{\mathrm{t}}=\left[\left(m_{\mathrm{f}, \mathrm{t}}-m_{0}\right) / m_{0}\right] * 100,
\end{aligned}
$$

where $m_{\mathrm{t}}$ is the mass of the specimen at time $\mathrm{t}$ (days), $m_{0}$ is the mass prior to immersion $(\mathrm{t}=0)$ and $m_{\mathrm{f}, \mathrm{t}}$ is the final mass of the specimen kept in the oven until constant mass after $t$ days of immersion in the ISS.

\section{Bioactivity Tests}

The bioactive behavior of the prepared bone-cement formulations was studied over a period of 30 days. Cylindrical specimens were immersed immediately after preparation in a simulated body fluid (SBF: $142.0 \mathrm{~m} M \mathrm{Na}^{+}, 5.0 \mathrm{~m} M \mathrm{~K}^{+}$, $2.5 \mathrm{~m} M \mathrm{Ca}^{2+}, 1.5 \mathrm{~m} M \mathrm{Mg}^{2+}, 147.8 \mathrm{~m} M \mathrm{Cl}^{-}, 4.2 \mathrm{~m} M \mathrm{HCO}_{3}^{-}$, $\left.1.0 \mathrm{~m} M \mathrm{HPO}_{4}^{2+}, 0.5 \mathrm{~m} M \mathrm{SO}_{4}^{2-}\right)$. The specimens were removed at intervals of $76 \mathrm{~h}$ and 7, 14, and 30 days, rinsed with distilled water, and dried at room temperature. One group of specimens was then gold-coated by ion sputtering and subsequently observed in a Leica Cambridge S360 scanning electron microscope (SEM). Another group of specimens was left uncoated for energy-dispersive spectroscopy (EDS) analysis.

The formulations presented in Table I were chosen to determine if any of the materials used to prepare the bone cements has inhibitory effects on the apatite formation ability of the composites. In some of them the glass BG was replaced by other bioactive fillers (Groups D and E), whereas in others one or more components of the formulation were excluded (Groups A and C). Groups F, G, and H are analogous to groups B3, B0, and E, respectively. The only difference is the monomer used: HEMA instead of a mixture of MMA and AA.

The bioactive discs of SCA were immersed in SBF under the following conditions:

1. Discs immersed alone (control discs)

2. Discs immersed together with specimen B0, after 2 days of immersion of the bone cement

3. Discs immersed alone in the same container where specimens of B0 were immersed for 2 days. 


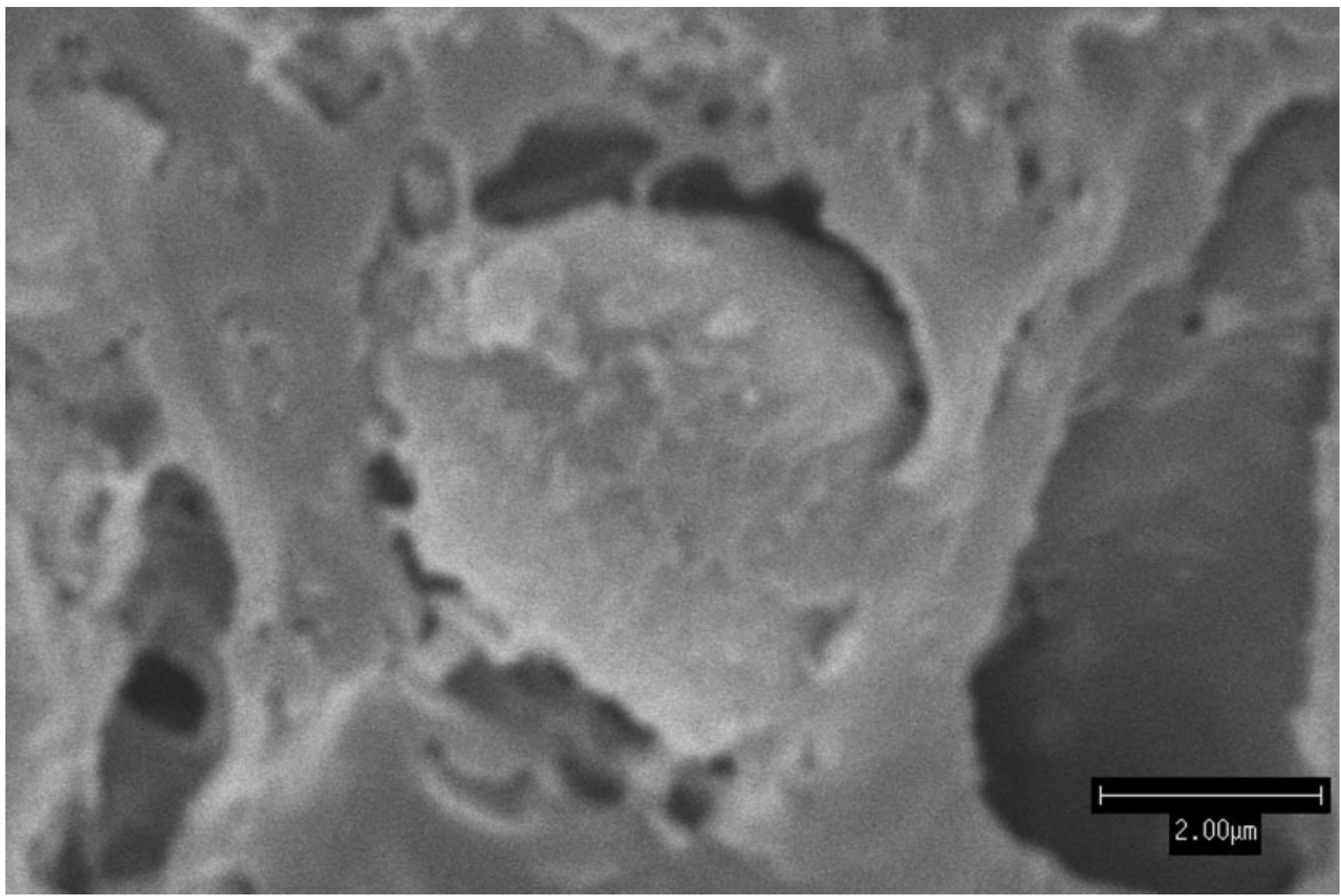

Figure 2. SEM micrograph of a detail of the glass/polymer interface after immersion in ISS.

The reason for these experimental conditions was to assess the effect of components released from the bone cement on the apatite formation ability of the referred discs. Groups 2 and 3 were chosen to compare the effect of the components released during the first days of immersion (Group 3) with those released during the whole immersion period (Group 2).

\section{Statistical Analysis}

One-way analysis of variance (ANOVA) was performed to test for the significance of means for the formulations of series B (B0, B1, B2, and B3). Whenever significant differences were found, a post-hoc test (Duncan's multiple-range test $)^{21}$ was then applied to all possible pairs of means in order to find which of them did not follow the null hypothesis. For testing differences among Palacos ${ }^{\circledR} \mathrm{R}$ and the composite

TABLE II. pH Evolution During Immersion in ISS

\begin{tabular}{ccc}
\hline & \multicolumn{2}{c}{$\mathrm{pH}$ at } \\
\cline { 2 - 3 } Formulation & 7 Days & 14 Days \\
\hline B0 & 4.5 & 4.2 \\
B1 & 5.6 & 5.5 \\
B2 & 6.0 & 5.9 \\
B3 & 6.2 & 6.2 \\
\hline
\end{tabular}

formulations, student's $t$ tests for independent samples were performed. ${ }^{21}$ The normality of the data was checked by constructing a normal probability plot of the residuals for each studied property. The resulting distribution was a straight line, confirming the normality assumption.

In all tests, significant differences were considered if the $p<0.05$. All tests were performed with the Statistica ${ }^{\circledR} 5.0$ (StatSoft) software for statistical analysis.

\section{RESULTS AND DISCUSSION}

\section{General Materials Characterization}

Figure 1(a,b) shows the evolution of WU and WL for the different formulations as a function of the immersion time in ISS. The data show (a) the initial kinetics of water uptake for the compositions containing glass is faster; (b) after the first week, the behavior was the opposite, with the composites showing a slower kinetics until an equilibrium in water uptake is reached; (c) independently of the amount of glass added, for long immersion times the water uptake was approximately the same for all composites (around 90\% of the value for the base matrix); (d) in general, for each given time point, the formulations with higher WU showed lower WL, and vice versa; (e) the approach of WL values of composition 


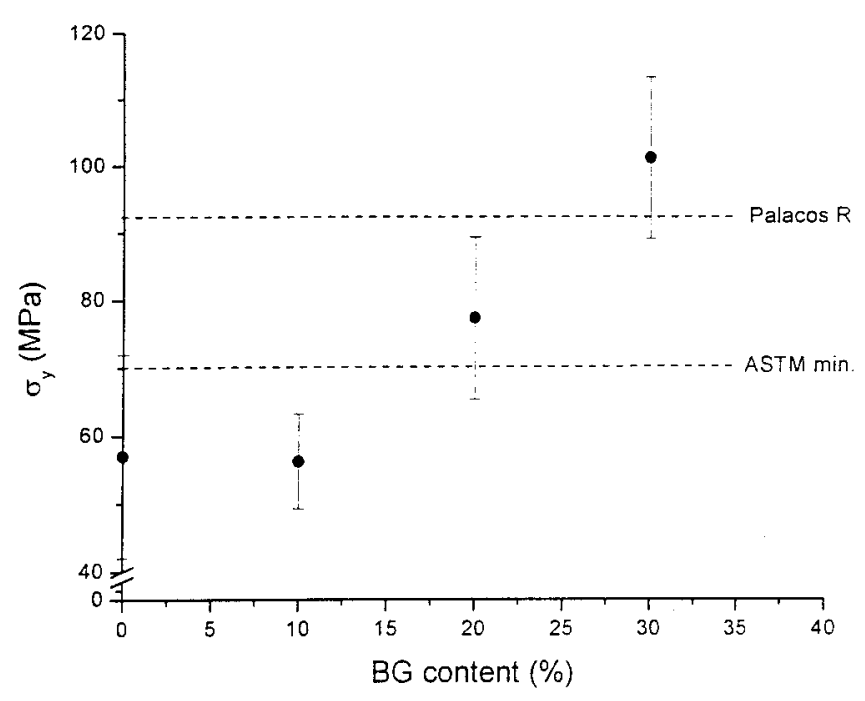

a)

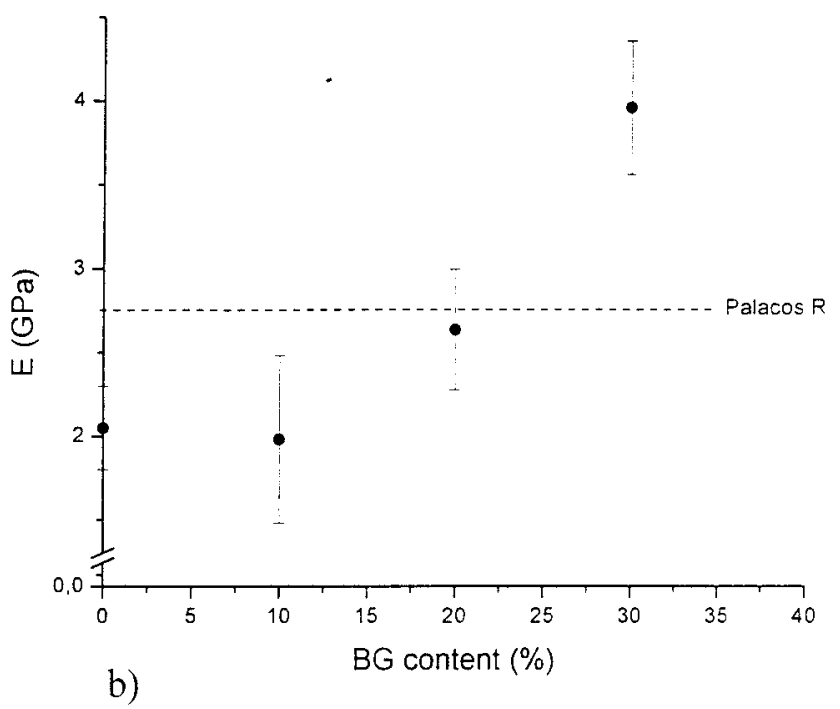

Figure 3. Mechanical properties of the composites: (a) yield compressive stress, (b) compressive modulus. The lines correspond to the minimum values required by the ASTM and ISO standards and to the values obtained for Palacos ${ }^{\circledR}$ R.

B1 to those of formulations B2 and B3 occurred at the same time (approximately 30 days) when the WUs of the respective formulations were also approaching a common value.

A previous article has already shown that the most determinant factor for the WU of this systems was the ratio of MMA/AA, with the amount of starch playing only a minor role. ${ }^{15}$ This fact can explain the behavior observed herein: because the MMA/AA ratio was kept constant, the small decrease in WU was due to the decreased amount of SCA (from $60 \%$ to $30 \%$ as the BG amount was increased from 0 to $30 \%$ ). The lack of a strong interaction between the polymer and the ceramic, leading to void spaces around the glass

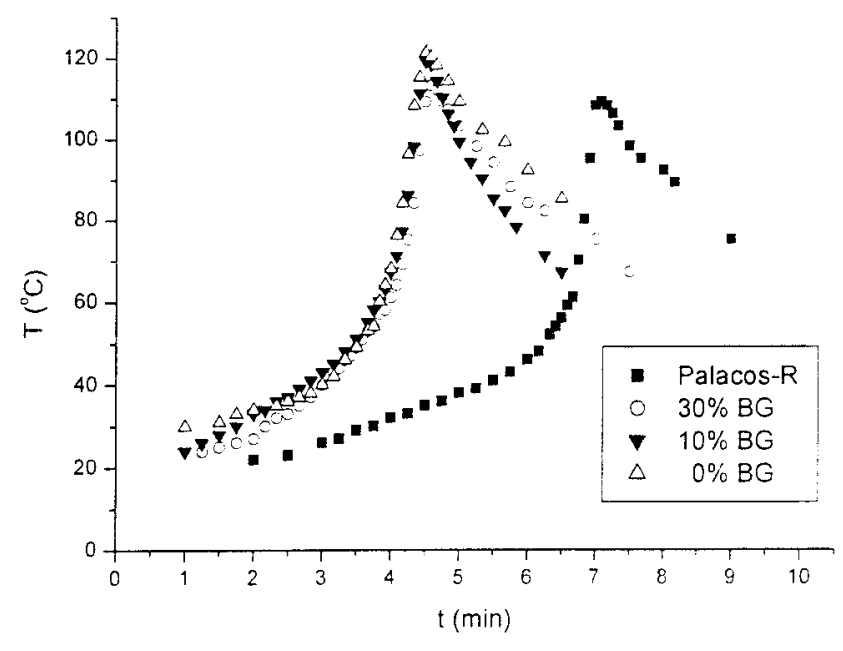

Figure 4. Curing curves of selected specimens.

particles (Figure 2), could be responsible for the faster kinetics of water uptake during the first days, allowing an easier penetration of water through these voids [Figure 1(a)]; in a second stage (from 7 to 30 days) the diffusion through the matrix predominates (because the voids are quickly filled) and in this case the glass is not only an inert material, but can act as an obstacle for water diffusion. Therefore, the higher the polymeric content, the higher the amount of water sorbed and the faster is this sorption. These results correlate well with the observed WL: The formulations with glass, because of the water uptake in the poor interface, are expected to lose mass faster and to a higher extent. This occurred because some small glass particles could be removed from the matrix, but mainly because of the exchange of cations between the glass and the solution and to the loss of soluble silica in the form of $\mathrm{Si}(\mathrm{OH})_{4}$ to the solution. ${ }^{22}$

This exchange of alkaline-earths from the glass with $\mathrm{H}^{+}$/ $\mathrm{H}_{3} \mathrm{O}^{+}$from the solution would keep the $\mathrm{pH}$ at higher values, counterbalancing the effect of AA released to the solution. As Table II shows, there was a consistent increase in $\mathrm{pH}$ with the increase of $\mathrm{BG}$ amount, for the studied time periods (the $\mathrm{pH}$ at time $t=0$ was 7.4 for all cases).

It is noteworthy that for degradation periods longer than 2 months, no difference was found in the behavior of the composites, regardless of the content of glass added.

Regarding the mechanical properties on the dry state [ $24 \mathrm{~h}$ after preparation, Figure $3(a, b)]$, the addition of more then

TABLE III. Curing Parameters

\begin{tabular}{lccc}
\hline Formulation & $T_{\max }\left({ }^{\circ} \mathrm{C}\right)$ & $t_{\mathrm{s}}(\min )$ & $t_{\mathrm{d}}(\mathrm{s})$ \\
\hline B0 & $112 \pm 8.5$ & $3.8 \pm 0.77$ & $19.3 \pm 1.5$ \\
B1 & $115 \pm 5.5$ & $3.4 \pm 0.33$ & $24.7 \pm 5.5$ \\
B2 & $114 \pm 9.2$ & $3.3 \pm 0.38$ & $33.3 \pm 5.8^{\mathrm{a}}$ \\
B3 & $116 \pm 2.5$ & $3.7 \pm 0.54$ & $65.0 \pm 7.4^{\mathrm{b}}$ \\
Palacos-R & $107 \pm 2.6^{\mathrm{c}}$ & $6.8 \pm 0.75^{\mathrm{b}}$ & - \\
\hline
\end{tabular}

${ }^{a}$ Significant difference against B0.

b Significant differences against all the previous formulations (in the same column).

${ }^{\mathrm{c}}$ Significant difference against B3. 


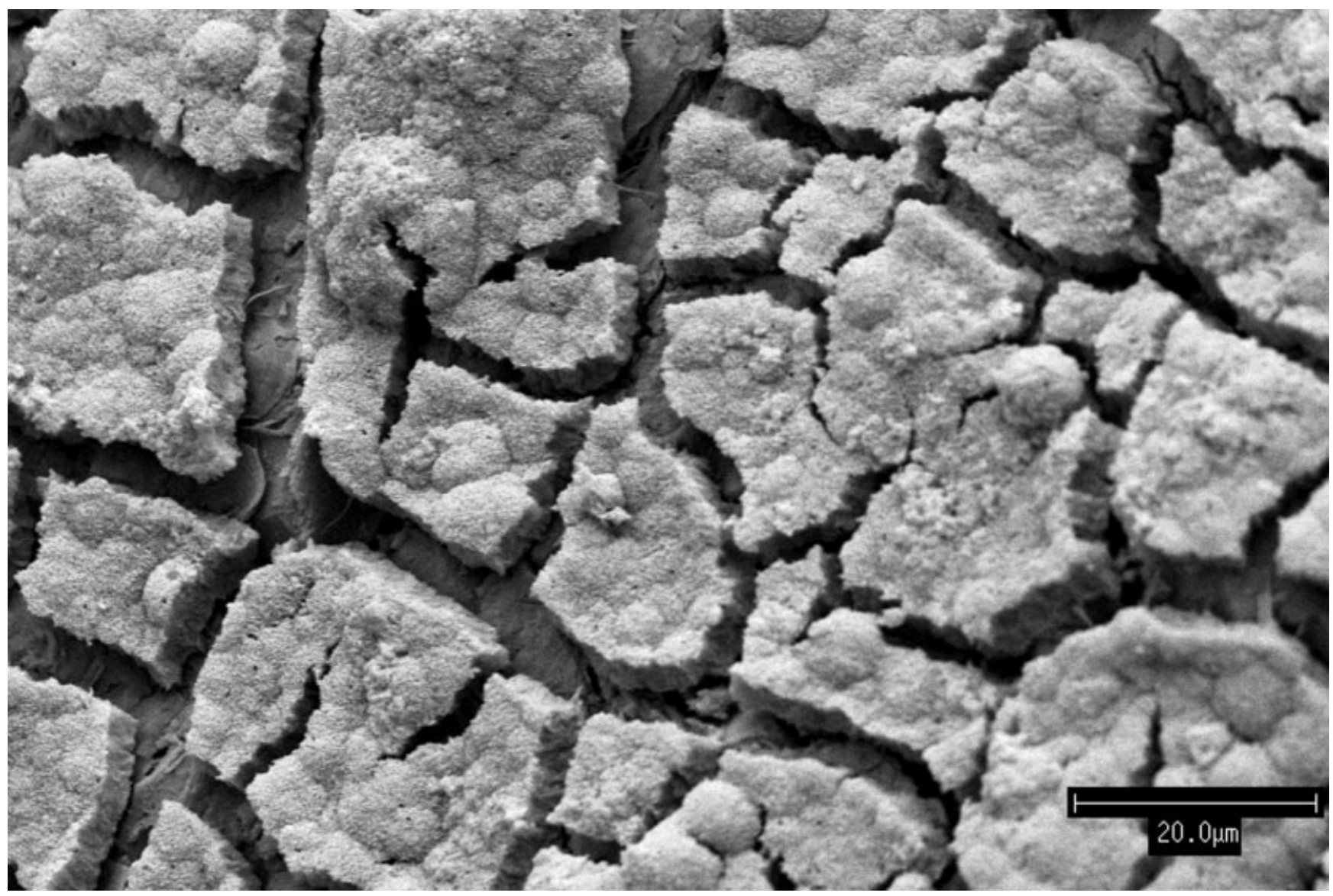

Figure 5. SEM micrograph showing a calcium-phosphate layer on the surface of a specimen from Group C, after 30 days of immersion in SBF.

$20 \%$ of the glass promoted significant improvements in the compressive behavior, so it was possible to attain formulations with properties that exceeded the requirements of the ASTM or ISO standards. This formulation showed properties better than one commercial bone cement $\left(\right.$ Palacos $\left.^{\circledR} \mathrm{R}\right)$, which was used here for comparison purposes: The yield stress was approximately the same and the compressive modulus was significantly higher. Two of the developed formulations (B0 and B2) were also subjected to tensile tests, in order to determine the effects of the glass on these properties. As is usual for noncoupled composites, the poor interface induces a poor load transmission from the matrix to the filler and limits the enhancement of tensile properties: Although the tensile modulus increased from $1.64 \pm 0.048 \mathrm{GPa}(\mathrm{B} 0)$ to $2.12 \pm 0.29 \mathrm{GPa}(\mathrm{B} 2)$, the ultimate tensile strength, for the same formulations, decreased from $40.4 \pm 6.5 \mathrm{MPa}$ to $30.4 \pm$ $3.8 \mathrm{MPa}$.

Figure 4 shows one curing curve for each of the formulations developed, as well as for Palacos ${ }^{\circledR} R$, whereas Table III shows the means and averages for the three studied parameters. A one-way ANOVA performed on formulations $\mathrm{B} 0-\mathrm{B} 3$ (that is, excluding $\mathrm{Palacos}^{\circledR} \mathrm{R}$ ) showed that significant differences were found only in $t_{\mathrm{d}}$. This seemed quite surprising, because the addition of inert fillers (glass, TCP, HA) is usually associated with de- creases in $T_{\max }$ and increases in $t_{\mathrm{s}} \cdot{ }^{23-25}$ However, in those works the filler was always added to purely MMA-based cements. In one case, the ratio S/L was increased from the typical $2 / 1$ to approximately $5 / 1$ (due to the high amount of glass ceramic added) ${ }^{23}$ and the decrease in $T_{\max }$ is due to the very small amount of liquid monomer in the formulation. It should be also noted that the PMMA, which is the usual solid component of conventional bone cements, plays an active role in the polymerization of the monomer and setting of the cement. ${ }^{26}$ The polymer is soluble in the monomer and the MMA can diffuse into the organic matrix of the powder, therefore leading to a matrix polymerization of MMA in the presence of the preformed polymer. When the filler is substituted for PMMA, this matrix polymerization will be hindered and more monomer will polymerize in the bulk; however, as the filler is inert (regarding the polymerization process), it will retard the polymerization, increasing the setting time and the time span of curing and decreasing the $T_{\max }$, because the heat of polymerization is released for a prolonged time. ${ }^{25}$

In the present hydrophilic bone cements, however, the solid component is always inert; the only possible interaction is grafting of AA onto the SCA. ${ }^{14}$ This means that the heat released depends only on the available amount of monomer, which will always polymerize in the bulk state. Therefore, the 


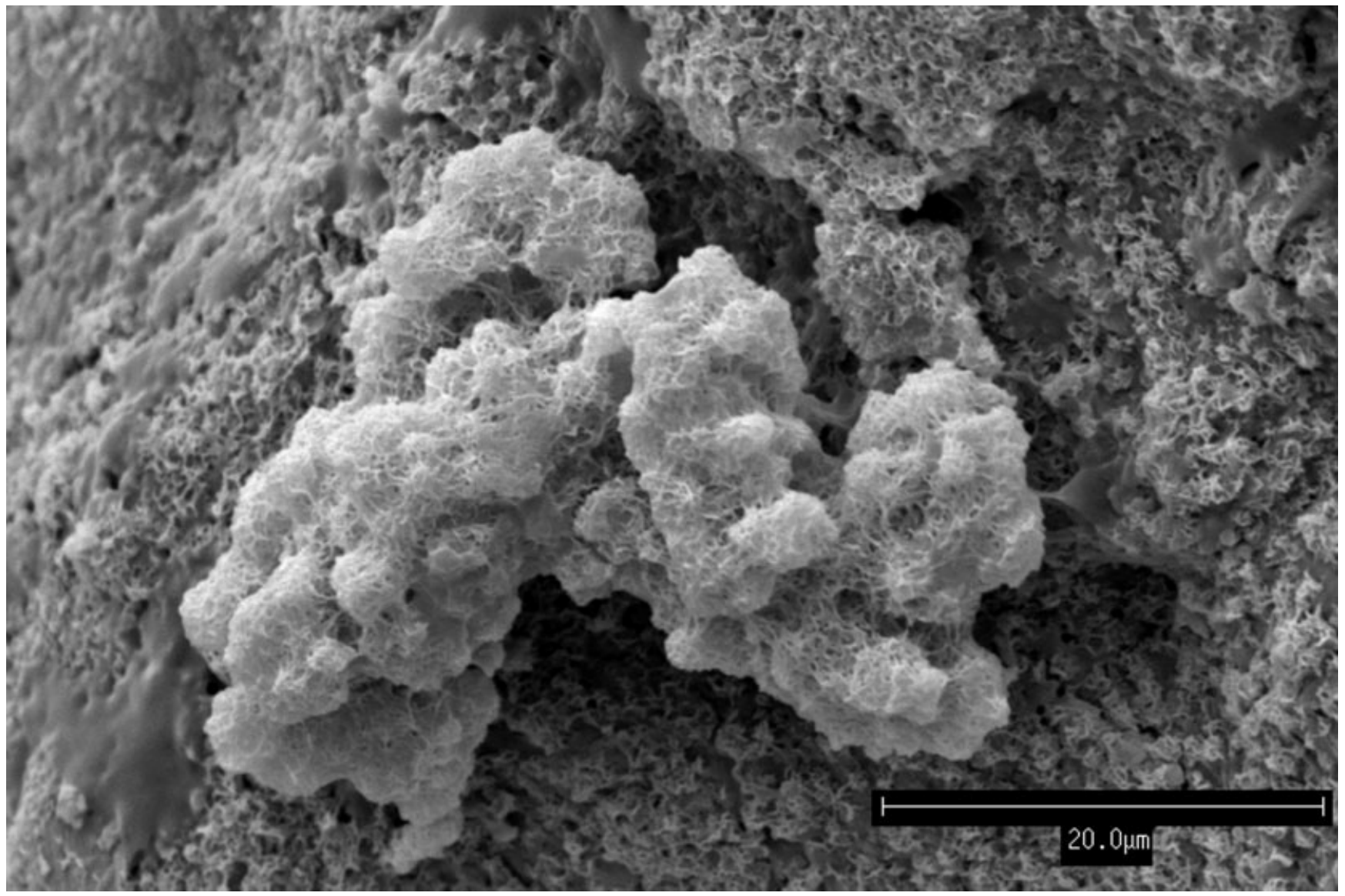

Figure 6. SEM micrograph showing calcium-phosphate nuclei on the surface of a specimen from Group F, after $76 \mathrm{~h}$ of immersion in SBF.

addition of glass particles is not expected to have any influence on the curing parameters of the system if the powder amount is kept constant. Only the $t_{\mathrm{d}}$ was extended with higher amounts of glass (Table III). It is hypothesized that this is due to the lower volume fraction of the powder with increasing filler content, due to the higher density of the glass. This improves the wetting conditions, because the constant liquid amount is soon exhausted, with higher volume fraction, for wetting the particles, and the mixture reaches the dough state earlier.

The Palacos ${ }^{\circledR} \mathrm{R}$ results, included here for comparison, are also shown in Table III. The $T_{\max }$ was not significantly different when compared to the hydrophilic bone cements (except for formulation B3). However the $t_{\mathrm{s}}$ was significantly longer. These values are not in agreement with the usual values published (approximately $70^{\circ} \mathrm{C}$ and $9.5 \mathrm{~min}$, respectively ${ }^{27}$ ) because a different measurement procedure was used, as outlined in the Materials and Methods section: storage of the material at $4^{\circ} \mathrm{C}$, mixing at room temperature for 1 min, and measurement at $37^{\circ} \mathrm{C}$. This different procedure was performed in order to better simulate the real conditions under which cement would be implanted. It seems that the curing parameters should still be improved, by means of using retarders/inhibitors, which do not negatively affect mechanical properties. ${ }^{28}$

\section{Bioactivity Tests}

Specimens containing $20 \%$ and $30 \%$ of bioactive glass were prepared for immersion in SBF. Even after 30 days of immersion, no signs of calcium phosphate layer formation were found on the surface. This seemed very surprising, because this same family of cements has previously shown a bioactive behavior when reinforced with HA. ${ }^{14}$ In order to identify the causes of this behavior, several formulations were prepared specially for bioactivity tests, as explained in the Preparation of Bone Cements section and in Table I.

Specimens of all these formulations were immersed in SBF for up to 30 days, for SEM and EDS analysis (Materials and Methods). Also, discs of the bioactive SCA/ $\mathrm{KMnO}_{4}$ material were immersed in SBF under the conditions shown in the Bioactivity Tests section.

From all these groups, a calcium phosphate $(\mathrm{CaP})$ layer was only observed in specimens from $\mathrm{C}$ (after 30 days of immersion), $\mathrm{F}$ (after 7 days; at $76 \mathrm{~h}$ nuclei were already observed) and $\mathrm{H}$ (after 7 days). $\mathrm{CaP}$ agglomerates were observed on the surface of specimens from Group E (after 14 days) and on the surface of the control discs (after 7 days). Together, these results point out that AA, whenever in solution, inhibits the formation of a $\mathrm{CaP}$ layer even in surface active materials, such as the glass BG. ${ }^{16}$ As the bone cements 
are immersed in SBF immediately after preparation (to simulate as close as possible their application in clinical situation) it is expected that they will release monomers or oligomers of AA to the solution, which will then inhibit the formation of $\mathrm{CaP}$ on the surface of bone cements or other materials present in the same solution. This fact explains the lack of any layer/agglomerate on the specimens from Groups A and D, as well as on the discs from Groups 2 and 3.

Once a CaP layer grew on the surface of both hydrophobic (MMA, Group C, Figure 5) and hydrophilic (HEMA, Group F, Figure 6) formulations, the glass, the matrix, or interactions between them could not be responsible for the lack of bioactivity of the studied system. The existence of a calcium phosphate layer on the surface of specimens from Groups $F$ and $\mathrm{H}$, but not on those from Group $\mathrm{G}$, also proves that the bioactive behavior was due to the incorporation of glass, and not to the use of HEMA (although tests with MMA without glass were not performed, this is a well-known nonbioactive material).

The composition of the coatings was assessed by EDS. Figure 7 shows the spectra of specimens from Group $\mathrm{H}$ immersed either in SBF or ISS, together with the spectrum of Bioglass ${ }^{\circledR} 45 \mathrm{~S} 5$ particles. After 7 days of immersion, the layer on the specimen immersed in SBF contained mainly $\mathrm{Ca}$ and $\mathrm{P}$ [Figure 7(a)]. The Si peak might be due to the silicon present in the glass under the layer. This was corroborated by the spectra of the specimen immersed in ISS, which shows silicon as the main element present on the surface [Figure 7(b)], and of the glass, which shows the peak of Si as the most intense [Figure 7(c)]. Therefore, the $\mathrm{Ca}$ and $\mathrm{P}$ appearing on the surface of the specimen immersed in SBF should be due to the precipitation of a calcium phosphate layer, because these elements would be dissolved from the glass when it is immersed in an isotonic saline solution. In this last case, only silicon would remain on the surface, explaining the intense peak for this element observed in Figure 7(b).

The tests performed with the bioactive discs indicated that the inhibitory effect is due to the AA in solution, and not to the AA present as a comonomer in the bone cement. Even the discs immersed in SBF after removal of the bone-cement specimen (which have been immersed for 2 days, Group 3) did not show apatite formation, showing that the dissolved AA is the inhibitor, and not the bone-cement device itself (that is, not the AA incorporated in the cement).

A discordant finding was the appearance of small agglomerates of $\mathrm{CaP}$ (confirmed by EDS analysis) around Bioglass ${ }^{\circledR}$ particles in specimens of Group E after 14 days of immersion (which contains AA in the formulation, Figure 8). A possible explanation for this behavior is the very high reactivity of Bioglass ${ }^{\circledR},{ }^{22}$ which induces bioactivity (after 7 days) even if added in concentrations as low as $10 \mathrm{wt} \%{ }^{29}$ Here it was present in $30 \mathrm{wt} \%$, and the agglomerates were found only after 14 days of immersion. It seems that this high reactivity compensated for the inhibitory effect of AA.

Similar results were found by other authors. Kamitakahara et al. $^{30}$ found that AA or polyAA inhibited the formation of apatite on the surface of AW glass ceramic even when the

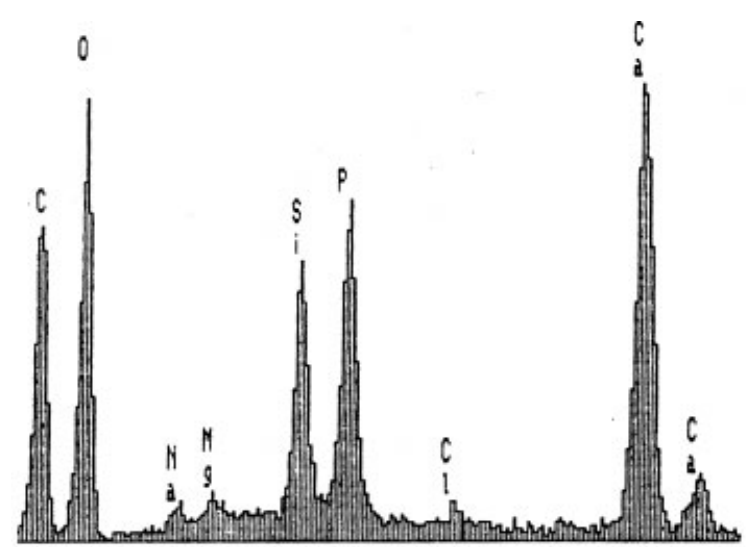

(a)

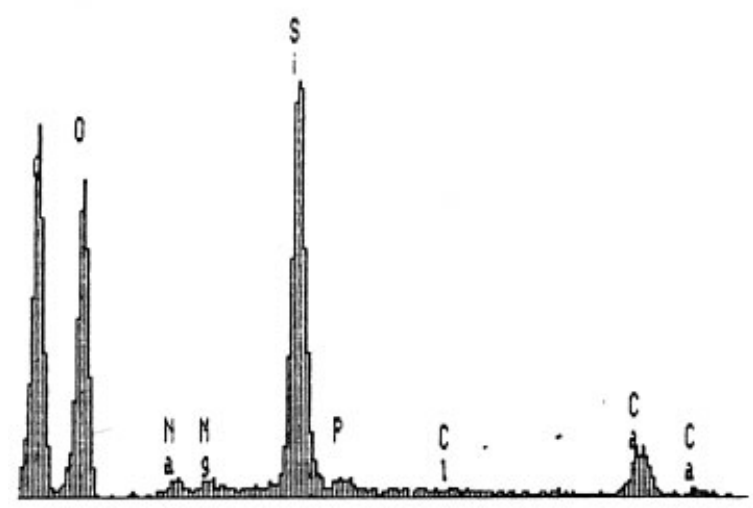

(b)

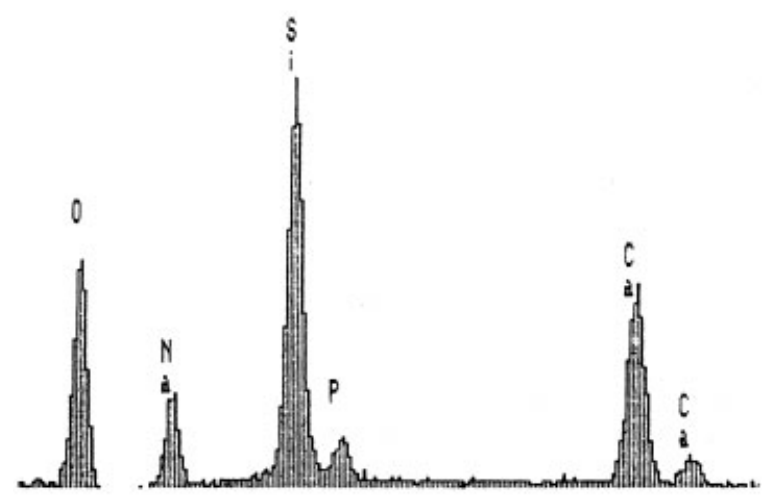

(c)

Figure 7. EDS spectra of the surface of specimens from Group $\mathrm{H}$ after 7 days of immersion in SBF (a) or ISS (b). EDS spectrum of the particles of Bioglass ${ }^{\circledR} 45 S 5$ (c).

concentration of polyAA was as low as $0.1 \mathrm{ppm}$. This was not due to $\mathrm{pH}$ changes, because both $\mathrm{HCl}$ and tartaric acid allowed the apatite growth. Kato et al. ${ }^{31}$ found results very similar to the ones reported here: When in solution, polyAA inhibited the crystallization of $\mathrm{CaCO}_{3}$, although poly (glutamic acid) did not. However, when the same solution was used in contact with a solid substrate of poly (ethylene-coacrylic acid) (80/20 wt/wt), rhombohedral calcite crystals were formed, once more showing that the inhibition effect of AA is confined to the dissolved species. 


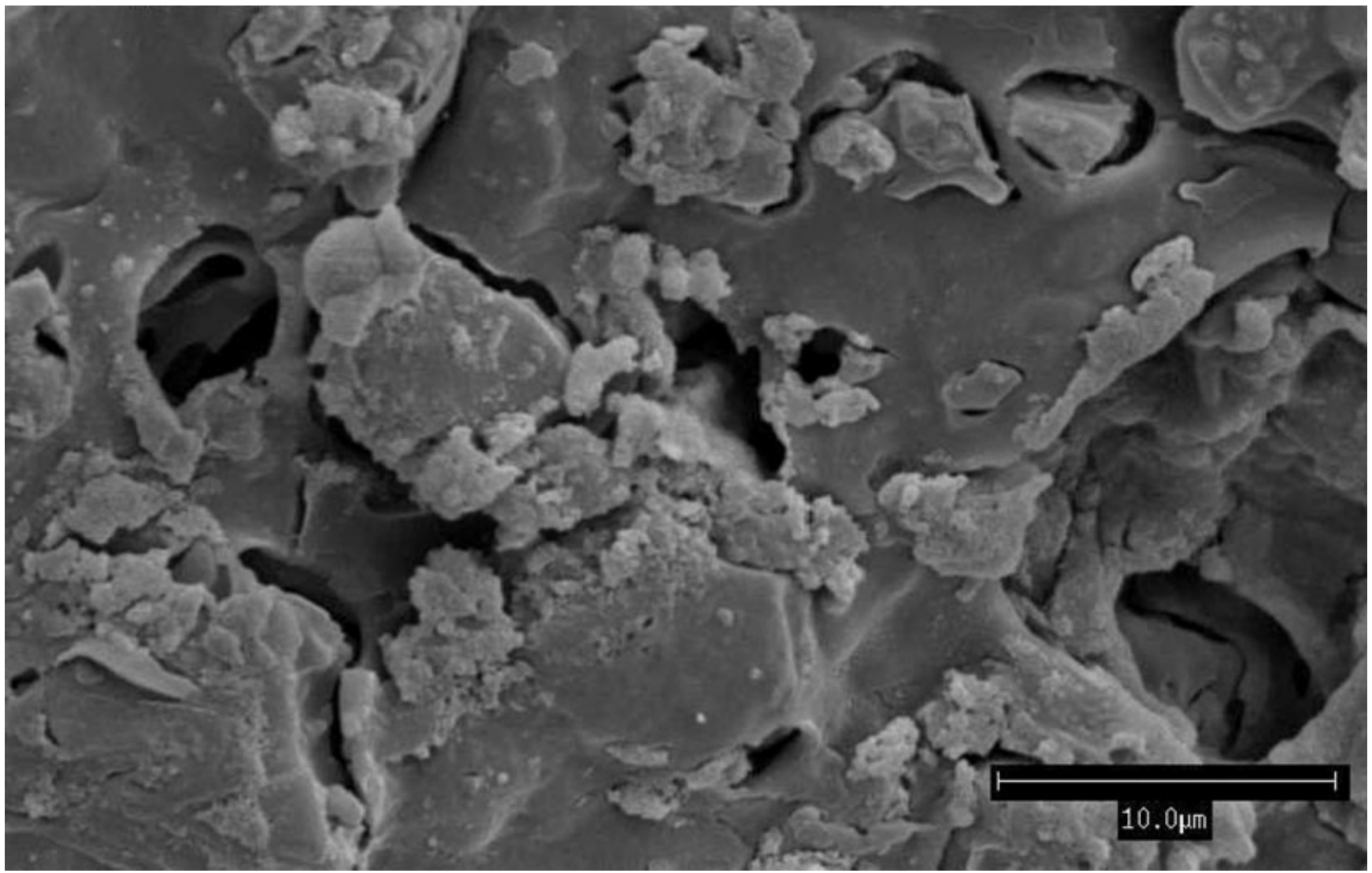

Figure 8. SEM micrograph showing calcium-phosphate agglomerates on the surface of a specimen from Group E, after 14 days of immersion in SBF.

\section{CONCLUSIONS}

Composites of bone cement containing hydrophilic and degradable components could be successfully produced and presented some advantages when compared to pure HBCs or to commercial formulations. Some of the formulations presented mechanical properties in the range required by ASTM and ISO standards, and even better than a typical commercial bone cement. The addition of glass permitted the $\mathrm{pH}$ of the surrounding media to be increased, which dropped because of the initial leaching of AA. This should generate fewer adverse reactions after implantation. Moreover, it led to an increase in the dough time without significantly changing the setting time or maximum polymerization temperature.

Compositions containing AA did not show bioactivity unless a very reactive glass was employed, showing that a coupled influence of low-reactivity glass and inhibitor substance was responsible for the lack of bioactivity. The inhibitor substance was determined to be the AA leached out from the specimens due to incomplete polymerization, because formulations containing only MMA or HEMA were bioactive when filled with either glass. Therefore, in order to obtain highly bioactive bone cements, HEMA should be used as the hydrophilic substance and more reactive glasses as the bioactive component. These may even allow apatite formation inside the pores generated during degradation of the degrad- able component, creating a strong adhesion to bone once the cement is implanted.

The authors acknowledge Dr. I. H. Pashkuleva for helping in the preparation and purification of the chemicals used in this study. L. F. B. also acknowledges Fundação Coordenação de Aperfeiçoamento de Pessoal do Ensino Superior (CAPES-Brasília, Brasil) for the PhD grant. This work was partially supported by FCT Foundation for Science and Technology, through funds from the POCTI and/or FEDER programs.

\section{REFERENCES}

1. Boesel LF, Mano JF, Elvira C, San Román J, Reis RL. Hydrogels and hydrophilic partially degradable bone cements based on biodegradable blends incorporating starch. In: Chiellini E, editor. Biodegradable polymers and plastics. Dordrecht: Kluwer Academic; 2003. p 243-260.

2. Lewis G. Properties of acrylic bone cement: state of the art review. J Biomed Mater Res Appl Biomater 1997;38:155-182.

3. Deb S. A Review of improvements in acrylic bone cements. J Biomater Appl 1999;14:16-48.

4. Shinzato S, Nakamura T, Kokubo T, Kitamura Y. PMMA-based bioactive cement: Effect of glass bead filler content and histological change with time. J Biomed Mater Res 2002;59:225232.

5. Harper EJ, Braden M, Bonfield W. Mechanical properties of hydroxyapatite reinforced poly(ethylmethacrylate) bone cement after immersion in a physiological solution: Influence of a silane coupling agent. J Mater Sci Mater Med 2000;11:491-497. 
6. Morita S, Furuya K, Ishihara K, Nakabayashi N. Performance of adhesive bone cement containing hydroxyapatite particles. Biomater 1998;19:1601-1606.

7. Elvira C, Vázquez B, San Román J, Levenfeld B, Ginebra P, Gil $\mathrm{X}$, Planell JA. Acrylic bone cements incorporating polymeric active components derived from salicylic acid: Curing parameters and properties. J Mater Sci Mater Med 1998;9:679-685.

8. Mroczkowski ML, Gilbert JL, Bhatia K, Hasenwinkel JM. Mechanical characterization of two-solution bone cement. In: Proceedings of the Society for Biomaterials Annual Meeting; 2003. p 480.

9. Pereira CS, Cunha AM, Reis RL, Vázquez B, San Román J. New starch-based thermoplastic hydrogels for use as bone cements or drug-delivery carriers. J Mater Sci Mater Med 1998; 9:825-833.

10. Taguchi T, Kishida A, Akashi M. Hydroxyapatite formation on/in poly(vinyl alcohol) hydrogel matrices using a novel alternate soaking process. Chem Lett 1998;8:711-712.

11. Gomes ME, Ribeiro AS, Malafaya PB, Reis RL, Cunha AM. A new approach based on injection moulding to produce biodegradable starch based polymeric scaffolds. Biomaterials 2001; 22:883-889.

12. Elvira C, Mano JF, San Román J, Reis RL. Starch-based biodegradable hydrogels with potential medical applications as drug delivery systems. Biomaterials 2002;23:1955-1966.

13. Sousa RA, Kalay G, Reis RL, Cunha AM, Bevis MJ. Injection molding of a starch/EVOH blend aimed as an alternative biomaterial for temporary applications. J Appl Polym Sci 2000;77: 1303-1315.

14. Espigares I, Elvira C, Mano JF, Vázquez B, San Roman J, Reis RL. New partially degradable and bioactive acrylic bone cements based on starch blends and ceramic fillers. Biomaterials 2002;23:1883-1895.

15. Boesel LF, Mano JF, Reis RL. Optimization of the formulation and mechanical properties of starch based partially degradable bone cements. J Mater Sci Mater Med 2003. Forthcoming.

16. Oliveira JM, Correia RN, Fernandes MH. Surface modifications of a glass and a glass-ceramic of the $\mathrm{MgO}-3 \mathrm{CaO} \cdot \mathrm{P}_{2} \mathrm{O}_{5}-\mathrm{SiO}_{2}$ system in a simulated body fluid. Biomaterials 1995;16:849854.

17. Elvira C, Levenfeld B, Vázquez B, San Román J. Amine activators for the "cool" peroxide initiated polymerization of acrylic monomers. J Polym Sci A Polym Chem 1996;34:2783-2789.

18. Pashkuleva I, Marques AP, Vaz F, Reis RL. Surface modification of starch based biomaterials can simultaneously enhance cell adhesion and proliferation and induce bioactivity. In: Pro- ceedings of the European Conference on Biomaterials; 2003.p T103.

19. ISO 5833/2: implants for surgery-Acrylic resin cements. Orthopaedic application. Geneva, Switzerland: International Organization for Standardization; 1992.

20. ASTM F451-86: Standard specification for acrylic bone cement. In: Annual book of ASTM standards: Medical devices; emergency medical services. Philadelphia: American Society for Testing and Materials; 1986.

21. Montgomery DC. Design and analysis of experiments (3rd ed.). Singapore: John Wiley \& Sons; 1991.

22. Hench LL. Bioceramics: from concept to clinic. J Am Ceram Soc 1991;74:1487-1510.

23. Shinzato S, Kobayashi M, Mousa WF, Kamimura M, Neo M, Kitamura Y, Kokubo T, Nakamura T. Bioactive polymethyl methacrylate-based bone cement: Comparison of glass beads, apatite- and wollastonite-containing glass-ceramic, and hydroxyapatite fillers on mechanical and biological properties. J Biomed Mater Res 2000;51:258-272.

24. Harper EJ. Bioactive bone cements. Proc Inst Mech Eng $\mathrm{H}$ 1998;212:113-120.

25. Yang JM. Polymerization of acrylic bone cement using differential scanning calorimetry. Biomaterials 1997;18:1293-1298.

26. Lautenschlager EP, Stupp SI, Keller JC. Structure and properties of acrylic bone cement. In: Ducheyne P, Hastings GW, editors. Functional behaviour of orthopaedic biomaterials. Volume II, Applications. Boca Raton, FL: CRC Press; 1984. pp 87-119.

27. Kühn KD. Bone cements. Heidelberg: Springer; 2000.

28. Kobayashi M, Nakamura T, Kikytani T, Kawanabe K, Kokubo $\mathrm{T}$. Effect of polymerization reaction inhibitor on mechanical properties and surface reactivity of bioactive bone cement. J Biomed Mater Res 1998;43:140-152.

29. Leonor IB, Sousa RA, Cunha AM, Zhong ZP, Greenspan D, Reis RL. Novel starch Thermoplastic/Bioglass ${ }^{\circledR}$ composites: Mechanical properties, degradation behaviour and in-vitro bioactivity. J Mater Sci Mater Med 2002;13:1-7.

30. Kamitakahara M, Kawashita M, Kokubo T, Nakamura T. Effect of polyacrylic acid on the apatite formation of a bioactive ceramic in a simulated body fluid: fundamental examination of the possibility of obtaining bioactive glass-ionomer cements for orthopaedic use. Biomaterials 2001;22:3191-3196.

31. Kato T, Suzuki T, Amamiya T, Irie T, Komiyama M. Effects of macromolecules on the crystallization of $\mathrm{CaCO}_{3}$ the formation of organic/inorganic composites. Supramol Sci 1998;5:411415 . 